\title{
Cardiopulmonary bypass-assisted surgery for the treatment of Xp11.2 translocation/TFE3 gene fusion renal cell carcinoma with a tumor thrombus within the inferior vena cava: A case report
}

\author{
GUANCHEN ZHU，XUEFENG QIU，XIANCHEN CHEN，GUANGXIANG LIU，GUTIAN ZHANG, \\ WEIDONG GAN and HONGQIAN GUO
}

\begin{abstract}
Department of Urology, Nanjing Drum Tower Hospital, The Affiliated Hospital of Nanjing University Medical School, Nanjing, Jiangsu 210008, P.R. China
\end{abstract}

Received December 17, 2014; Accepted September 4, 2015

DOI: $10.3892 / \mathrm{ol} .2015 .3739$

\begin{abstract}
Renal cell carcinoma (RCC) accounts for $85-90 \%$ of kidney cancers, which in turn account for $2-3 \%$ of all malignant tumors in adults. Xp11.2 translocation/TFE3 gene fusion RCC is currently classified as a distinct type of RCC. $\mathrm{RCC}$ is capable of invading the renal vein and inferior vena cava to form a tumor thrombus. The incidence of RCC with tumor thrombi within the renal vein or inferior vena cava is $7-10 \%$ in China. In the present case report, the patient underwent radical resection of the renal tumor and removal of the tumor thrombus, assisted by cardiopulmonary bypass, for the treatment of Xp11.2 translocation/TFE3 gene fusion RCC. The patient was followed-up for 12 months subsequent to treatment. The patient's renal function remained within the normal range, and computed tomography examination revealed no evidence of disease recurrence or metastases. The present case report aimed to provide a reference for the development of guidelines for the diagnosis and treatment of Xp11.2 translocation/TFE3 gene fusion RCC.
\end{abstract}

\section{Introduction}

Kidney cancer accounts for 2-3\% of all malignant tumors in adults, with renal cell carcinoma (RCC) accounting for $85-90 \%$ of kidney cancers (1). According to the World Health Organization classification criteria for renal cancer, published in 2004 (2), RCC with Xp11.2 translocation/TFE3 gene fusion

Correspondence to: Professor Weidong Gan or Professor Hongqian Guo, Department of Urology, Nanjing Drum Tower Hospital, The Affiliated Hospital of Nanjing University Medical School, Building 2, 321 Zhongshan Road, Nanjing, Jiangsu 210008, P.R. China

E-mail: dr.gwd@yeah.net

E-mail: dr.guohongqian@gmail.com

Key words: cardiopulmonary bypass, Xp11.2 translocation/TFE3 gene fusion, tumor thrombus, surgery, diagnostic is classified as a distinct type of RCC. RCC with Xp11.2 translocation/TFE3 gene fusion primarily occurs in adolescents, and demonstrates no significant gender variation (2). The malignancy of RCC with Xp11.2 translocation/TFE3 gene fusion is considered to be relatively low. Therefore, few cases of advanced tumors have been previously reported (2).

$\mathrm{RCC}$ is capable of invading the renal vein and inferior vena cava to form a tumor thrombus; in China, this occurs in $7-10 \%$ of RCC cases (3). It is widely accepted that tumor thrombus of the inferior vena cava is not a decisive indicator for determination of the prognosis of patients with RCC (4).

Surgery is typically the first choice of treatment for RCC, due to its insensitivity to chemotherapy and radiotherapy. Clinical studies have demonstrated a certain efficacy of multi-kinase inhibitors, such as sunitinib, sorafenib and mTOR/MET kinase inhibitor, in treating rapidly progressive metastatic Xp11.2 RCC in adult patients $(5,6)$. However, the optimal treatment approach for Xp11.2 RCC remains to be determined.

The current study presents the case of a patient with Xp11.2 translocation/TFE3 gene fusion RCC, who underwent radical resection of a renal tumor and removal of the tumor thrombus, assisted by cardiopulmonary bypass.

\section{Case report}

The current report presents the case of a 46-year-old male, who was admitted to the Nanjing Drum Tower Hospital (Nanjing, China) in September 2013, due to right abdominal pain. Renal magnetic resonance imaging (MRI) results suggested a diagnosis of RCC with hemorrhage, accompanied by an inferior vena cava tumor thrombus and enlarged retroperitoneal lymph nodes. Vascular ultrasound examination indicated that a tumor thrombus had formed within the inferior vena cava, and that it extended to the level of the diaphragm. Following the exclusion of surgical contraindications, radical resection of the right kidney, and removal of the tumor thrombus within the inferior vena cava under cardiopulmonary bypass, were performed. Briefly, following exposure of the right kidney and inferior vena cava, cardiopulmonary bypass was established via intubation of the ascending aorta, inferior vena cava and right atrium. The 
A
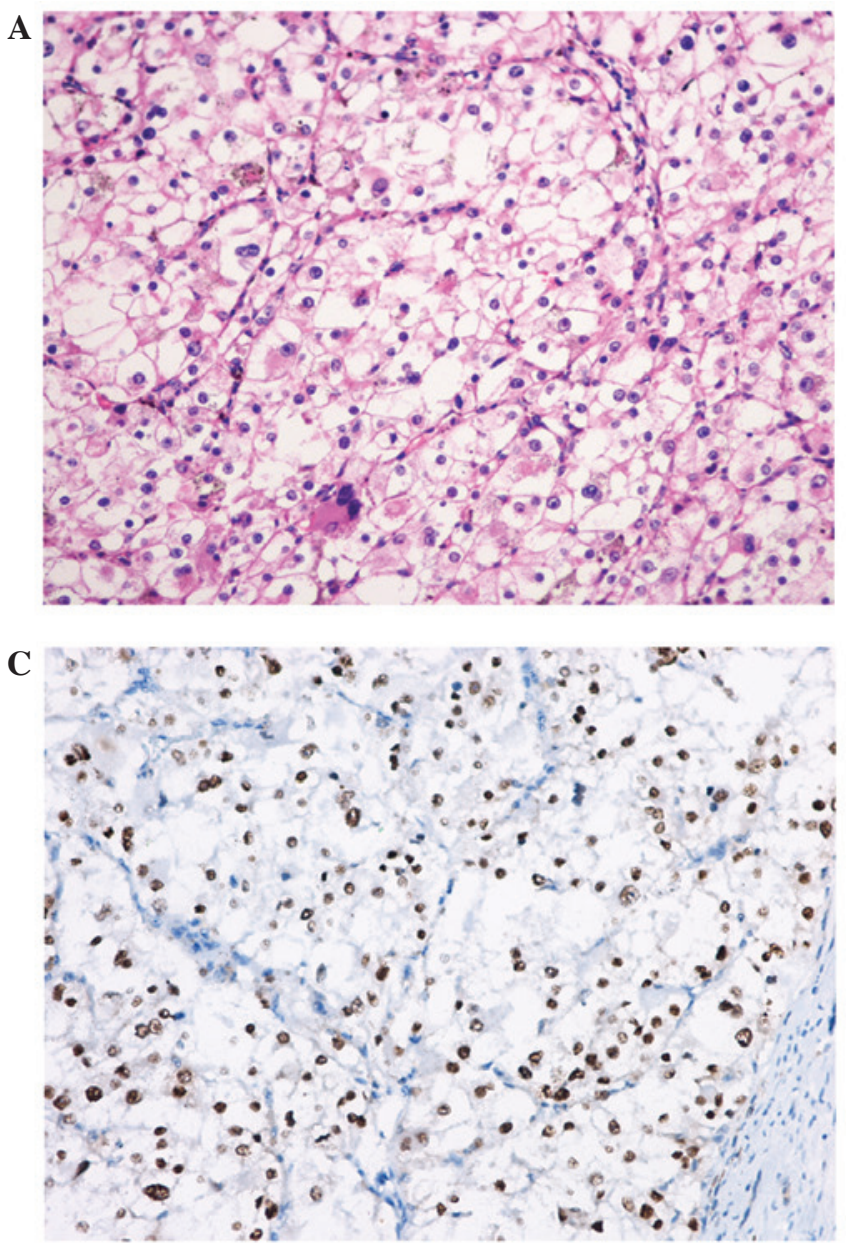

$\mathbf{B}$

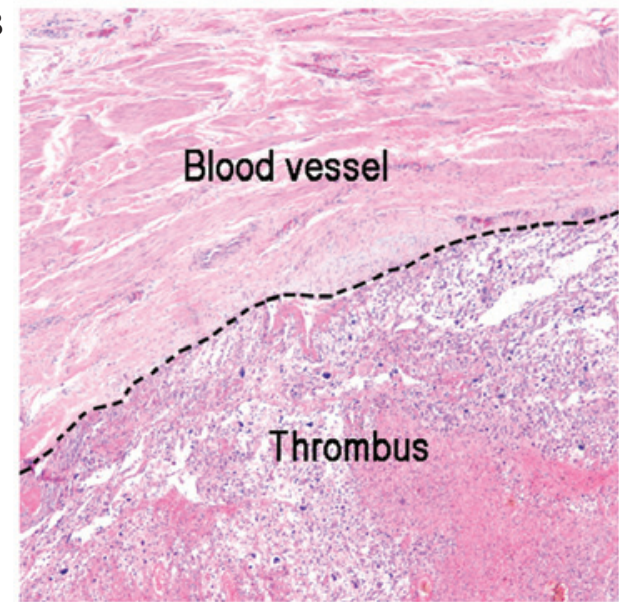

D

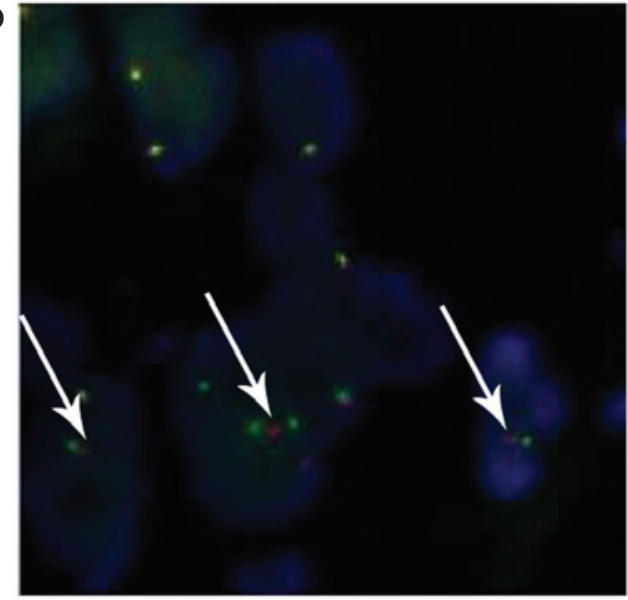

Figure 1. Immunohistochemical analysis of RCC tumor samples. (A) H\&E staining of Xp11.2 translocation/TFE3 gene fusion RCC (magnification, x100). (B) H\&E staining of the tumor thrombus within the inferior vena cava (magnification, $\mathrm{x} 40$ ). (C) Positive expression of TFE3 protein in Xp11.2 translocation/TFE3 gene fusion RCC indicated by immunohistochemistry (magnification, x100). (D) Fluorescence in situ hybridization with polyclonal break-apart probes revealed fusion signals (yellow) and a pair of red and green split signals (white arrows), representing a TFE3 gene translocation in the X chromosome of the tumor cells (magnification, x100). H\&E, hematoxylin and eosin; RCC, renal cell carcinoma.

tumor thrombus was removed by dissecting the vena cava following relocation of the tumor thrombus from the superior vena cava to the inferior vena cava. Heparin $(400 \mathrm{U} / \mathrm{kg})$ and low-dose protamine ( $2 \mathrm{mg} / \mathrm{kg}$; for the reversal of heparin) were administered during and following the cardiopulmonary bypass. Subsequently, the right kidney was resected.

Combined with the results of TFE3 gene fusion protein immunohistochemistry and fluorescent in situ hybridization (FISH), a diagnosis of Xp11.2 translocation/TFE3 gene fusion-related RCC was considered (Fig. 1A-D). The patient was discharged two weeks subsequent to surgery. Chemotherapy was administered following discharge of the patient from hospital; the patient was initially started on oral sorafenib (400 mg, twice daily), and 6 months later was switched to oral sunitinib (50 mg/day) for 4 weeks on and 2 weeks off.

The patient was followed up for 12 months subsequent to treatment. The patient's renal function remained within the normal range, while computed tomography examination revealed no evidence of disease recurrence or metastases. Therefore, the possibility of recurrence during this follow-up period was ruled out. However, determining the long-term prognosis of patient still requires long-term follow-up.

\section{Discussion}

According to the tumor thrombus classification devised by Neves and Zincke (7), based on the extent of dissection, the tumor thrombus in the present case was defined within the third classification, and described as a tumor thrombus within the inferior vena cava, extending to the level below the diaphragm. MRI, which demonstrates advantages for the detection of vena cava tumor thrombi, was utilized in the present case to detect and evaluate the vena cava tumor thrombus (8). Following exclusion of the presence of distant metastasis, surgery was performed.

It has been accepted that surgical removal of the tumor and thrombus is the typical first choice treatment strategy for non-metastatic RCC, even with the co-occurrence of an inferior vena cava thrombus (9). In the present case, cardiopulmonary bypass was utilized to assist with the removal of the tumor thrombus within the inferior vena cava (Fig. 1B). Cardiopulmonary bypass may be able to extend operating times and surgical space for surgeons (10). In addition, cardiopulmonary bypass markedly reduces the potential risk of bleeding during surgery on large blood vessels, simplifying the surgical resection of tumor thrombi within the inferior 
vena cava, and those located within the right atrium (9). It is widely accepted that immunohistochemical staining of certain proteins specifically expressed in Xp11.2 translocation/TFE3 gene fusion RCC, including TFE3 gene fusion-associated protein, is the primary method for diagnosis of this type of tumor $(11,12)$. Argani et al $(13)$ reported that the sensitivity and specificity of immunohistochemistry in the diagnosis of tumors with Xp11.2 translocation/TFE3 gene fusion in the urinary system, and additional systems, was 99.6 and $97.5 \%$, respectively. In the present case, the tumor weakly expressed P504S, while strongly expressing CD117, human melanoma black 45 and TFE3 (Fig. 1C).

To date, eight specific genotypes have been reported in Xp11.2 translocation/TFE3 gene fusion RCC, and in three of these the site of gene fusion cannot be clearly identified. Xp11.2 translocation/TFE3 gene fusion RCC accounts for $\sim 1 \%$ of RCC diagnoses in adult patients (14). FISH with polyclonal break-apart probes, has been used as a rapid and accurate diagnostic method for detecting TFE3 gene fracture in tumor tissue. This is due to this method's specific ability to bind with each end of fragments of TFE3 DNA $(15,16)$. In the present case, FISH was used to confirm the diagnosis of Xp11.2 translocation/TFE3 gene fusion RCC. As indicated in Fig. 1D, tumor cells demonstrated a fusion signal (yellow) and a pair of red and green split signals, representing TFE3 gene translocations in the $\mathrm{X}$ chromosome. This result confirmed that FISH may be useful as an alternative, effective method for the diagnosis of Xp11.2 translocation/TFE3 gene fusion RCC.

Follow-up of the current patient is ongoing. To the best of our knowledge, the present case is the first to report the successful surgical treatment of Xp11.2 translocation/TFE3 gene fusion RCC with inferior vena cava tumor thrombus surgery, using cardiopulmonary bypass. The present report may provide a reference for the development of guidelines for the diagnosis and treatment of Xp11.2 translocation/TFE3 gene fusion RCC.

\section{References}

1. Kabala JE: The kidneys and ureters. In: Textbook of Radiology and Imaging. Sutton D (ed). Churchill Livingstone, London, p953, 2003.

2. Lopez-Beltran A, Scarpelli M, Montironi R and Kirkali Z: 2004 WHO classification of the renal tumors of the adults. Eur Urol 49 798-805, 2006.
3. Li XF, Zhou FJ, Qiu SP, et al: Diagnosis and treatment of renal cell carcinoma with vena cava tumor thrombi. Ai Zheng 23: 1074-1067, 2004 (In Chinese).

4. Cost NG, Delacroix SE Jr, Sleeper JP, Smith PJ, Youssef RF, Chapin BF, Karam JA, Culp S, Abel EJ, Brugarolas J, et al: The impact of targeted molecular therapies on the level of renal cell carcinoma vena caval tumor thrombus. Eur Urol 59: 912-918, 2011.

5. Choueiri TK, Mosquera JM and Hirsch MS: A case of adult metastatic Xp11 translocation renal cell carcinoma treated successfully with sunitinib. Clin Genitourin Cancer 7: E93-94, 2009.

6. Malouf GG, Camparo P, Oudard S, et al: Targeted agents in metastatic Xp11 translocation/TFE3 gene fusion renal cell carcinoma (RCC): A report from the Juvenile RCC Network. Ann Oncol 21: 1834-1838, 2010

7. Neves RJ and Zincke H: Surgical treatment of renal cancer with vena cava extension. Br J Urol 59: 390-395, 1987.

8. Guo HF, Song Y and Na YQ: Value of abdominal ultrasound scan, $\mathrm{CT}$ and MRI for diagnosing inferior vena cava tumour thrombus in renal cell carcinoma. Chin Med J (Engl) 122: 2299-2302, 2009.

9. Chiappini B, Savini C, Marinelli G, Suarez SM, Di Eusanio M, Fiorani V and Pierangeli A: Cavoatrial tumor thrombus: Single-stage surgical approach with profound hypothermia and circulatory arrest, including a review of the literature. J Thorac Cardiovasc Surg 124: 684-688, 2002.

10. Paul JG, Rhodes MB and Skow JR: Renal cell carcinoma presenting as right atrial tumor with successful removal using cardiopulmonary bypass. Ann Surg 181: 471-473, 1975.

11. Argani P, Hicks J, De Marzo AM, Albadine R, Illei PB, Ladanyi M, Reuter VE and Netto GJ: Xp11 translocation renal cell carcinoma (RCC): Extended immunohistochemical profile emphasizing novel RCC markers. Am J Surg Pathol 34: $1295-1303,2010$

12. Argani P and Ladanyi M: The evolving story of renal translocation carcinomas. Am J Clin Pathol 126: 332-334, 2006.

13. Argani P, Lal P, Hutchinson B, Lui LY, Reuter VE and Ladanyi M: Aberrant nuclear immunoreactivity for TFE3 in neoplasms with TFE3 gene fusions: A sensitive and specific immunohistochemical assay. Am J Surg Pathol 27: 750-761, 2003.

14. Liu Y, Xu B and Chen F: Recent advances in renal cell carcinoma associated with Xp11.2 translocations/TFE gene fusions. N Am J Med Sci 5: 43-47, 2012.

15. Klatte T, Streubel B, Wrba F, Remzi M, Krammer B, de Martino M, Waldert M, Marberger M, Susani M and Haitel A: Renal cell carcinoma associated with transcription factor E3 expression and Xp11.2 translocation: Incidence, characteristics, and prognosis. Am J Clin Pathol 137: 761-768, 2012.

16. Kuroda N, Katto K, Tanaka Y, Yamaguchi T, Inoue K, Ohara M, Mizuno K, Hes O, Michal M and Lee GH: Diagnostic pitfall on the histological spectrum of adult-onset renal carcinoma associated with Xp11.2 translocations/TFE3 gene fusions. Med Mol Morphol 43: 86-90, 2010. 